\title{
ESCOLA PÚBLICA E TRABALHO INFANTIL: FORMAÇÃO DE CRIANÇAS E ADOLESCENTES, NO INÍCIO DO SÉCULO, EM PORTO ALEGRE
}

\author{
Nilton Bueno Fischer*
}

SÍNTESE - Este artigo apresenta a relação existente entre a proposta de quatro escolas noturnas, criadas para crianças que trabalhavam nos serviços de capina nas ruas de Porto Alegre, e o processo mais amplo, de construção de futuros cidadãos, a partir da perspectiva positivista. A categoria analítica 'formação' permite explicar esse processo numa perspectiva relacionada à urbanização e industrialização, que estavam transformando a 'vida urbana' da cidade de Porto Alegre no primeiro quarto deste século. Dados retirados dos Relatórios da Intendência Municipal serviram de base para a explicitação de como efetivamente este processo de formação se desenvolveu.

PALAVRAS-CHAVE - trabalho infantil, formação, ensino noturno.
ABSTRACT - This article presents how four public night schools, created for children who work in capina services in the streets of Porto Alegre during the day, contributed to a general process of building future citizens, under positivist philosophy. Analytical category formation is used to explain this process in the general perspective of urbanization and industrialization that was changing the urban life of Porto Alegre in the first quarter of the twentieth century. Date from the Relatorios da Intendência Municipal help to understand how the formation was being developed in concrete forms.

KEY WORDS - children's work, formation, night schools.

\section{Introdução}

"Com o fim de proporcionar instrução elementar (ler, escrever e contar) às crianças pobres, que se ocupam no serviço de capina das ruas, e a outros, custeados pela Intendência, foi fundada a Escola Notuma Hilário Ribeiro em 13 de Maio de 1911."1

* Doutor em Educação, professor da Faculdade de Educação da Universidade Federal do Rio Grande do Sul (UFRGS). Em 1998, bolsista da Coordenação de Aperfeiçoamento de Pessoal de Nível Superior (CAPES) - Ministério da Educação, Pós-Doutorado (Universidade de Mlinois, Estados Unidos).

1 Conforme Relatório e Projecto de Orçamento para o exercício de 1914 apresentado ao Conselho Municipal pelo Intendente José Montaury de Aguiar Leitão. Este, como os demais dados empíricos referidos no presente artigo, consta do acervo do Projeto Integrado Conselho Nacional de Pesquisa 
A educação de crianças e adolescentes das classes subalternas, especialmente aquelas em situações de 'geração de renda', tem sido motivo de preocupações, estudos e políticas públicas recentes. Este artigo ${ }^{2}$ procura analisar tal temática numa perspectiva de resgate histórico, no primeiro quarto do século, na cidade de Porto Alegre. Em certo sentido, integra-se a estudos como os levados a efeito por Carvalho (1984) e Beisiegel (1974 e 1984), onde se focaliza prioritariamente a oferta de ensino noturno e respectivas políticas públicas de educação destinadas às classes subalternas.

Nosso propósito aqui visa destacar a contribuição da instituição 'escola pública' - através da sua internalidade e, em especial, de sua estrutura curricular para o processo de formação ${ }^{3}$ de crianças e adolescentes, a partir das relações entre os campos político, econômico e social.

\section{Cenánio}

Entre 1900 e 1920 a população de Porto Alegre passou de quase 100 mil habitantes para 180 mil (Spalding, 1967). A predominância era de uma população jovem que procurava obter acesso a, no mínimo, duas instâncias daquilo que seria considerado como 'direitos de cidadania': escola e trabalho. Na época, entre os diversos tipos de indústria, o número de trabalhadores jovens, entre 14 e 18 anos, era de 803 , equivalente a $9,9 \%$ da mão de obra ocupada. No campo político, Porto Alegre tinha na pessoa de seu intendente municipal, José Montaury, um legitimo representante do ideário positivista. Também ao longo desse período, os presidentes da Província do Rio Grande do Sul, Júlio de Castilhos e Borges de Medeiros, complementavam e garantiam a presença de políticas públicas, sob a perspectiva do positivismo, as quais, entre outras metas, buscavam oportunizar a incorporação dos setores subalternos à sociedade 'moderna'. A qualificada pesquisa de Tambara (1991) atesta essa orientação: “ ao proletariado é solicitada a função de vigiar a ação governamental no sentido de que atenda a verdades sociais. Propugnava assim o positivismo o seu papel de 'elevação moral' a partir do poder público no sentido de proporcionar aos trabaihadores efetivas condições de exercer sua função social. Para isso, uma condição indispensável era a universalização do ensino primário" (p. 67).

(Ministério de Ciência e Tecnologia) - CNPq/FAPERGs (Fundação de Amparo à Pesquisa do Rio Grande do Sul), Urbanidade e Cidadania: processos de formação e instauração de saberes (Subprojeto: Assistência Social e Formação). Os mesmos foram obtidos junto ao Arquivo Histórico de Porto Alegre, a partir dos Relatórios da Intendência Municipal, editados pela oficina gráfica do jornal A Federação.

2 A pesquisa que originou este artigo teve a participação de bolsistas da FAPERGS e CNPq. A eles meu reconhecimento, tanto pelo minucioso trabalho de coleta de dados, como pelo subsequiente registro. Nada disso seria possivel, entretanto, não fosse o eficiente assessoramento da prof ${ }^{\mathrm{a}}$ Maria Stephanou, coordenando o cotidiano das investigações. Vale destacar também a efetiva contribuição da bolsista Quézia Domingues, na etapa final da pesquisa.

3 O termo formação é aqui empregado em sentido mais amplo, conforme já referido em Fischer (1997) e, especialmente, em Desaulniers (1997), que afirma: "Este conceito envolve a aquisição de inúmeros conhecimentos, não se confundindo, porém, com instrução, já que o processo de formação implica o desenvolvimento de habilidades e atitudes, assim como a integração dos saberes à prática cotidiana na vida do formado." 


\section{As escolas}

A criação das quatro escolas municipais de ensino noturno, destinadas a crianças e adolescentes, foi uma decisão tomada pelo intendente José Montaury a fim de, atendendo aos princípios de manutenção de uma cidade limpa em seus aspectos físicos, garantir uma sinalização de mobilidade social (princípio positivista de seu partido) para crianças e adolescentes de rua; surge, assim, oferta de trabalho e educação. Segundo os Relatórios da Intendência Municipal, os critérios básicos para a localização das escolas (prédios e/ou 'salas'), resumiam-se nos seguintes: proximidade com a região onde as crianças e adolescentes trabalhavam, preferentemente onde estivesse a subsede do setor de limpeza do município; perto ou junto aos distritos municipais que se formaram a partir da autoridade municipal em lugares onde se ampliava o espaço urbano; ou ainda, perto de vilas onde estivessem morando os trabalhadores e os migrantes. Embora as discussões sobre a criação das escolas tivessem se iniciado em 1906, a primeira escola criada data de 13 de maio de 1911 e denomina-se Escola Hilário Ribeiro; logo após, em 2 de janeiro de 1912, foi a vez da Escola Bibiano de Almeida; a Escola Apolinário Porto Alegre surge em 4 de março de 1918 e a última com tais características, em 1927, denominada Marcos de Andrade. No sentido de garantir uma boa educação para essas crianças e adolescentes, o município procurava oferecer as melhores condições materiais para que as aulas se efetivassem normalmente. Entretanto, prédios alugados recebiam exigentes avaliações, verificando atender seus objetivos. Quando se trata de prédio próprio, os relatórios revelam boas condições para o ensino. Tais observações, acerca da qualidade das condições materiais, eram registradas principalmente quando ocorriam atividades especiais, como as festividades de entrega de resultados; ou quando da recepção aos novos professores e outros visitantes. Os itens arrolados nessas avaliações incluem aspectos referentes à ventilação (natural ou artificial), entre outros. Há referência à construção de ginásios para prática dos esportes e dos grounds, situados ao lado dos prédios, destinados especificamente ao futebol. O processo de formação dessas crianças e adolescentes - articulando trabalho e ensino, aproximando local de escola e local de trabalho (também dos pais) - incluía também um mecanismo de eficiente poder formador: os equipamentos de madeira usados nas escolas eram confeccionados na Casa de Correção da Cidade (Relatónio de 1926). A pedagogia do trabalho formava um universo bastante 'compreensivo' no qual a formação de 'bons hábitos' levava os alunos a respeitarem os bens produzidos por aqueles excluídos da sociedade.

\section{Os ahunos}

No relatório de 1926, palavras textuais revelam quem efetivamente deveria freqüentar as escolas municipais noturnas: "[jovens sem instrução] cujas ocupações diumas não permitiam freqüentar o ensino primário e que se ocupavam dos serviços de capina das ruas", bem como "filhos de progenitores empregados na limpeza pública". Mesmo com essa especificidade, havia também lugar para outro tipo de aluno como "todos aqueles que desejassem aprender as primeiras letras, mesmo os maiores de idade ou de nacionalidade estrangeira". A freqüência cons- 
tituiu-se um problema sério para a época. A média da freqüência das quatro escolas era de $60 \%$. Em princípio, duas explicações poderiam ser aqui arroladas. A primeira relacionada com a dificuldade de as crianças acompanharem os estudos, uma vez que chegavam cansadas em casa, por terem trabalhado ao longo do dia; a segunda, relacionada ao movimento de retorno às cidades do interior, junto aos familiares, de parte de algumas famílias, tendo em vista a carestia e a crise derivadas da Primeira Guerra, que repercutia nos reduzidos orçamentos domésticos.

Outro problema que se pode extrair dos documentos diz respeito ao aproveitamento escolar. De acordo com os dados constantes nos relatónios da Intendência, seu percentual fica abaixo de 18\%: (Escola Hilário Ribeiro: 5\%; Escola Bibiano de Almeida: $18 \%$ e Apolinário Porto Alegre: 8,4\%). Nesses registros é raro encontrar preocupação explícita por parte da Intendência que sinalize prováveis causas dessas taxas. Isto se confirma quando o menor percentual de aproveitamento se localiza justamente na escola na qual deveria haver as melhores condições de estudo, como foi o caso da Escola Hilário Ribeiro, onde do currículo constavam as inovações através das aulas de ginástica sueca e de aparelhos e aulas de música. Uma provável explicação para a irrevelevância diante dos resultados pode ser relacionada ao fato de que, em caso de continuidade nos estudos, o Instituto $\mathrm{Pa}$ robé seria a instituição a ser procurada e, nela, segundo o minucioso estudo de Stephanou (1989), a única exigência para ingresso consistia em saber ler e escrever, não necessitando da credencial do diploma.

\section{Música e esporte: preferências}

Os meninos demonstravam um alto interesse pelas aulas de música - o percentual é maior quanto menor a idade - e tinham altíssima freqüência nas aulas de ginástica. Estas últimas ocorriam três vezes por semana e eram identificadas como 'saudáveis folguedos da idade', motivo de intercâmbios, inclusive com equipes de escolas do vizinho país uruguaio. Havia competições intramuros, entre as escolas municipais e entre alunos da banda e das aulas regulares. As aulas de música eram estimuladas por sua dupla finalidade: fortalecia o aprendizado em outras disciplinas e possibilitava a obtenção de emprego futuro, na condição de músico profissional.

Em síntese, podemos dizer que documentos como estes Relatórios da Intendência vêm confirmar, mais uma vez, que a formação de crianças e adolescentes desse período histónico compreendeu um original e bem interligado processo entre os campos político, educacional e econômico. As diversas oportunidades oferecidas pelas escolas noturnas em torno de atividades curriculares, como aulas de música e de ginástica, bem como os esportes e os rituais das solenidades, tendem a ser mais significativas para formação do futuro cidadão do que os aspectos formais de mensuração de freqüência e do aproveitamento escolar. Desta forma, o conjunto das mudanças provocado pela cultura urbana em constituição, bem como 0 apoio de políticas públicas fundamentadas na doutrina positivista, transparecem no cotidiano desses alunos, freqüentadores das escolas públicas noturnas, em Porto Alegre, no primeiro quarto de século. 


\section{Referências bibliográficas}

BEISIEGEL, Celso de Rui. Estado e Educação Popular: um estudo sobre a educação de adultos. São Paulo: Pioneira, 1974. 1982.

CARVALHO, Celia Pezzolo de. Ensino notumo: realidade e ilusão. São Paulo: Cortez, 1984.

DESAULNIERS, Julieta Beatriz Ramos. "Formação e pesquisa: condições e resultados". Veritas, Porto Alegre, v. 42, n. 2, mar. 1993, p. 183-204.

FISCHER, Nilton Bueno. "Cidadania e ação social: contribuições a partir da categoria formação". Veritas, Porto Alegre, v. 42, n. 2, jun. 1997, p. 283-290.

SPALDING, Walter. Pequena história de Porto Alegre. Porto Alegre: Sulina, 1967.

STEPHANOU, Maria. Forjando novos trabalhadores: a experiência do ensino técnico profissional no Rio Grande do Sul (1890-1930). Porto Alegre (Dissertação de Mestrado). 1989.

TAMBARA, Elomar Antonio Callegaro. A Educação no Rio Grande do Sul sob o Castilhismo. Porto Alegre, UFRGS. (Tese de Doutorado). 1991. 